\title{
CANNABIS USE, TIME PERSPECTIVE AND RISK PERCEPTION: EVIDENCE OF A MODERATING EFFECT.*
}

*This is a revised version of a poster communication presented at the $18^{\text {th }}$ Annual Conference of the European Health Psychology Society, University of Helsinki (Finland) in June 2004.

Authors:

\section{THEMIS APOSTOLIDIS ${ }^{12}$; NICOLAS FIEULAINE ${ }^{13}$, LAURENT SIMONIN $^{1}$ and GERALDINE ROLLAND ${ }^{1}$}

\section{Affiliations:}

${ }^{1}$ Laboratoire de Psychologie Sociale, Université de Provence, Aix-en-Provence

${ }^{2}$ Institut National de la Santé et de la Recherche Médicale (INSERM), U-379

${ }^{3}$ GERA, Département de Psychologie Sociale, Université Lumière, Lyon

\section{Correspondence:}

Thémis APOSTOLIDIS (orresponding author) : Laboratoire de Psychologie Sociale, Université de Provence, 29 av. Robert Schuman, 13621 Aix-en-Provence cedex, France. Mail: aposto@up.univ-aix.fr .

Tel : ++33 442.953.815.

Nicolas FIEULAINE : GERA, Département de Psychologie Sociale, Université Lumière Lyon 2, 5 av. Pierre Mendès France, 69676 Bron cedex, France.

Laurent SIMONIN : Laboratoire de Psychologie Sociale, Université de Provence, 29 av. Robert Schuman, 13621 Aix-en-Provence cedex, France.

Géraldine ROLLAND : Laboratoire de Psychologie Sociale, Université de Provence, 29 av. Robert Schuman, 13621 Aix-en-Provence cedex, France. 


\section{Abstract:}

This study explores the relationship between time perspective (TP), cannabis use and risk perceptions associated to this substance. A sample of French students $(\mathrm{n}=198)$ were provided with a valid French version of the ZTPI scale. Risk perceptions linked to cannabis consumption were evaluated from a list of 22 items referring to different risks. Respondents were asked to declare how frequently they consumed this substance. Data analysis was based on firstly, ZTPI scores, secondly, declared consumption and finally, two risk perception indices which were established after factorial analysis. Results showed that TP acted as a significant predictor of both psychoactive substance use and of cannabis consumption frequency. Significant links between consumption and risk perception also appeared. A second series of analyses showed that TP acted as a moderating variable in this link between cannabis consumption and risk perception. These findings indicate that TP must be considered as a significant variable when analysing the complexity of contemporary cannabis use and suggests that further research in this area should be carried out.

\section{Key Words:}

Cannabis Use; Time perspective; ZTPI; Risk Perception; Young adults. 


\section{INTRODUCTION}

Over the last decade in France, as in many other European countries, the use of cannabis among adolescents and young adults has represented a major public health stake. French epidemiological surveys show that cannabis is the most commonly used illicit drug and estimate that by the end of adolescence, between 50 and 60 per cent of 18 year olds will have at least tried cannabis (Beck \& Legley, 2003a). These prevalent rates of cannabis experimentation have been steadily increasing since 1993 among both male and female students (Choquet, Beck, Hassler, Spilka, Morin \& Legleye, 2004), and even though cannabis consumption decreases over a period of time, 48.3 per cent of young adults under 25 years old had tried cannabis at least once (Beck \& Legley, 2003b). Nowadays, along with alcohol and tobacco, cannabis is the most widely used drug.

If epidemiological rates and increased cannabis use have been extensively documented, little is actually known about the psychosocial dynamics of consumption behaviour and the relationship to the substance established by consumers. Crucial questions are therefore raised in this particular contemporary social context in which nearly one in two young people admit to experimenting with an illicit substance - for example, the ordinary experiences of using and abusing cannabis; the place that consumption occupies in users' everyday lives or the way that several psychological variables may affect individuals' behaviours. In order to study these variables further, it is important to take into account that, among young people, cannabis use has become "normalised", in the sense of being commonplace (Hammersley, Jenkins \& Reid, 2001). In effect, the "normalisation" of cannabis use is related not only to a "statistical norm" but also to a "culturally" established one, as was put forward from a British context (Pearson, 2001). However, within a French context, although the use is "normalised", the way the substance is perceived still causes debates about its definition as a "drug" (Dany \& Apostolidis, 2002); debates that engage both the prohibition politics applied to its consumption and the prevention policies which are especially concerned with problematic or intensive use. Although cannabis is defined as a drug, this has not prevented political debates from arising concerning the substance use within the social context. Many researchers have noted that debates concerning the labelling of cannabis as a drug, beyond the ideological foundations of political and scientific arguments, have focused on the dangers of the substance, thus taking advantage of an uncertainty in scientific positions concerning the risks involved from substance use (Peretti-Wattel, 2000). 
Discussion, which includes legal attitudes towards users, primary preventive strategies and appropriate treatment, regarding these risks has now become a central part of social debates.

Cannabis consumers now have to balance a "normative tension"; that is to say "normalising" substance use and its illegality or the public health communications concerning associated risks. Thus, this balancing act involves on the one hand, creating a "positive" image of cannabis and considering it as a "soft" drug, its use as recreational, private choice or socially functional, and on the other hand, a "negative" image considering cannabis as a harmful drug, its use illegal or as the first step towards using more dangerous drugs (escalating theory). For consumers, managing the contradictory character of cannabis normalised and illicit or dangerous - establishes a specific relationship to the substance, which allows reconciling the private dimension of the practice with the institutional definition (Hammersley \& al., art. cit.). The first objective when reconstructing the substance's image is to get away from the "risky" label, which generally defines behaviour and individuals as "deviant" and/or "drug-takers". Because of the risk of stigmatisation, neutralisation strategies are established, which in fact create a distinction between cannabis and other drugs perceived as "hard" (Peretti-Wattel, 2003). Among these strategies, which include the differentiation between different contexts and patterns of use - namely whether to consume alone or in a group; at work or in the evening, redefining the dangers and effects of the substance occupies a central place (Ibid.). Thus, in order to be in harmony when using the substance, cannabis risk perceptions are susceptible to being restructured by the consumer, while psychologically distancing himself/herself from the "hard" drugs. These different cognitive neutralisation strategies, such as the "denial of risk" and the distinction between cannabis and "hard drugs" applied to risk perceptions were made obvious by Peretti-Wattel (2003). These strategies have a dynamic character and do not only rely on the experimental use of the substance. In order to be effective, these risk perceptions are modified and adjusted when consumption increases. Thus, risk perceptions appear essential when analysing the development of consumer behaviours; their increase, quitting or relapses (Boney-McCoy, Gibbons, Reis, Gerrard, Luus \& Von Wald Suka, 1992).

Within this framework, considering that substance use and abuse appear as complex social behaviours, analysing cognitive variables represents an essential issue and enables one to understand the relationship of young adults to cannabis, as well as its progression. Taking these variables into account appears more desirable and useful than other studies, which showed the intervention of general cognitive variables in the link between consumption and risk perceptions associated to the substance. Self-esteem, for example, seemed to play a 
moderating role in the link between tobacco consumption and changes in risk perceptions (Gibbons, Tami \& Alida, 1997), or sensation seeking appeared as moderating the link between risk evaluation and risky behaviours (Rosenbloom, 2003).

Among the variables involved in these strategies, Time Perspective (TP, Lewin, 1942) appears as particularly pertinent, despite it not being the aim of the research at this time. This psychological dimension concerns the relationship to the past, present and future, not only in the importance granted to every temporal register, but also in the negative or positive attitude linked to each. TP constitutes a socio-cognitive variable that influences perceptions and actions by marking them with a temporal composite. (Zimbardo \& Boyd, 1999). When studying substance use, TP was often seen as playing an important role and was thus revealed as predictive of psychoactive substance consumption (Hulbert \& Lens, 1988; Keough, Zimbardo \& Boyd, 1999; Alvos, Gregson \& Ross, 1993; Levy \& Earleywine, 2004), and cannabis use in particular (Wills, Sandy \& Yaeger, 2001; King \& Manaster, 1975). Usually these studies only consider the relationship to the substance from a behavioural dimension. Nevertheless, the role played by TP in risky behaviours is often analysed for its degree of effectiveness in relating to future consequences. (Strickland, Lewicki \& Katz, 1966; Lipscomb, 1989; Hall \& Fong, 2003). Thus, taking into account long-term consequences, perceived as risks, a future oriented TP would be negatively linked to the substance consumption. Inversely, a present centred TP would be linked to a lower risk concern, and therefore to a higher consumption (Wilde, 1982; Petry \& Bickel, 1998). Despite the importance of risk perceptions when analysing risky behaviours (Gerrard, Gibbons, Benthin \& Hessling, 1996), few studies have worked on the link between TP and risk perceptions.

The aims of this research are:

- $\quad$ To verify the established links between TP and substance use (e.g., Keough, Zimbardo \& Boyd, 1999), using a sample of French students,

- To analyse the influence of TP and cannabis consumption on risk perceptions,

- To explore the role played by TP in the link between cannabis consumption and risk perception, focusing on the neutralisation strategies such as risk denial and distinction to the "hard" drugs (Peretti-Wattel, 2003), that can emerge depending on consumption and its progression.

\section{METHOD}




\section{Participants and Procedure}

198 human science undergraduate students from two French universities (located in Aix-enProvence), aged from 18 to 25 years old ( $\mathrm{M}$ age $=21.8 ; \mathrm{SD}=1.96$ ), took part in this study on a voluntary basis. The sample was composed of 100 men $(\mathrm{M}$ age=22.35; $\mathrm{SD}=2.02)$ and 98 women $(\mathrm{M}$ age=21.3; $\mathrm{SD}=1.7)$. Participants were invited to fill in the questionnaire individually.

\section{Measures}

Classification fell into three groups: (1) Time perspective; (2) Risk perception; and (3) Substance use.

\section{Time Perspective}

TP was measured using the ZTPI (Zimbardo \& Boyd, 1999) in its French validated version (Apostolidis \& Fieulaine, 2004). ZTPI is a multidimensional scale which measures both TP in three temporal frames; the past, present and future, and the attitude related to each of them. It takes into account the motivational, emotional, cognitive and social aspects by an inventory of temporally marked propositions concerning beliefs, values and preferences that individuals associate with their experiences. This scale contains the following 5 subscales: "Past-Positive" (PP: nostalgic, positive construction of the past); "Past-Negative" (PN: aversive attitude towards the past); "Present-Fatalistic" (PF: hopeless, nihilistic attitude towards life); "Present -Hedonistic" (PH: orientation towards enjoyment and pleasure in the present) and "Future" (F: planning for and achievement of future goals). These temporal frames are represented by 54 items which are assessed on a 5-point Likert-type scale according to how characteristic each reply is of the respondent. The scores for the items in each sub-scale were calculated by the mean.

\section{Risk Perception}

In order to explore the perception of risks linked to cannabis, we created a questionnaire which was based on the analysis of 28 semi-structured interviews with young adults concerning cannabis. The aim of the interviews was to investigate how lay people perceive and make sense of risk by focusing on the particular content of common-sense thinking about the risks related to the consumption of cannabis (Joffe, 2003). Indeed, in order to understand 
the "normalizing" context of substance-use necessitates taking into consideration both the symbolic and social aspects of risk apprehension along with the scientific discourses regarding the use and abuse of cannabis. The chosen elements concerned different aspects of risk revealed by the interviewees, and are rooted in the debates throughout French society concerning the effects of cannabis use. Firstly, certain risks correspond to the scientific 'certainty domain' such as health risks and psychological dependence, while others are uncertain (neuron damage), or non-existent (an overdose). On one hand, some of the disclosed risks are inconclusive where cannabis is concerned, but on the other hand, correspond to established risks within the framework of "hard" drugs consumption such as heroin. When applied to cannabis, these risks can suggest a similarity to that of the "hard" drugs universe. Secondly, certain statements rejecting all noxious effects of the substance, such as losing selfcontrol, motivation and risks on driving, directly represent "risk denial". Finally, a third category of propositions, corresponding to a positive attitude towards the substance, focuses on its positive effects such as communication with friends and positive emotions. The questionnaire was constituted of 22 statements (see presentation of these items in Table 3), representative of each category and presented to participants in randomized order. For each statement, the participants were asked to rate their level of agreement on a 5 point Likert-type scale, ranging from strongly disagree (1) to strongly agree (5).

\section{Substance Use}

This research used a self-report questionnaire to assess the respondents' substance use. In order to assess the frequency of cannabis use, the respondents were asked to indicate how often they had used cannabis in the last year, month or day. This response format contained 5 levels of consumption; abstinent, experimental, occasional, repeated and regular, and was based on the criteria used in surveys conducted by the French Monitoring Centre for drugs and drug addiction (OFDT). Considering the strong prevalence of cannabis use among young adults in France (Beck, Legleye \& Peretti-Wattel, 2002), we added an additional level intensive $^{1}$. The distinction between these levels enabled us to evaluate the frequency of cannabis consumption, which in turn allowed us to analyse the eventual differences in the relationship to cannabis that can exist between those who consume in an experimental way and those who are engaged in a more regular or intensive manner. Moreover, it appeared to be more effective to study the possible influence of psychological or social variables in

\footnotetext{
${ }^{1}$ The measures of the several levels of use were defined in the questionnaire as follow: Abstinent, «to have never smoked cannabis »; experimental, " to have smoked cannabis but not during the last 12 months »; occasional, «to have smoked cannabis less than 10 times during the last 12 months »; repeated, «to have smoked cannabis less than 10 times during the last 30 days »; regular, «to have smoked cannabis more than 10 times during the last 30 days »; intensive, « to have smoked cannabis at least once per day ».
} 
consumption and related cognitions (McCusker, Roberts, Douthwaite \& Williams, 1995; McMillan, Sherlock \& Conner, 2003) than the simple dichotomy between users and non-users (Resnicow, Smith, Harrison \& Drucker, 1999). Hence, we evaluated the quantity of consumption from the declared number of joints smoked, and then took into account other consumed substances- whether they be licit, such as alcohol and tobacco, or illicit, such as ecstasy, LSD, cocaine or heroin - which had been indicated by the respondents.

\section{RESULTS}

\section{Descriptive Statistics}

Table 1 recapitulates the sample characteristics for declared consumption and principal measures for men and women. One can observe the high rates of cannabis, tobacco and alcohol use among the population questioned. These results confirm those established by the French national investigations showing "statistic normalisation" of cannabis use, even though in this sample rates appeared higher. However, it is notable that chi-square tests in our sample did not reveal significant differences in cannabis consumption levels between men and women, apart from a difference in the " intensive » level $(p=.07)$, where we observed a higher rate in men than in women. Other substance declared consumption did not appear to make any significant difference between sexes.

Table 1 about here

The alpha coefficients were calculated for the ZTPI five sub-scales ("Past-Positive", $\mathrm{N}=8, \alpha=.70$; "Past-Negative", $\mathrm{N}=9, \alpha=.77$; "Present-Fatalistic", $\mathrm{N}=7, \alpha=.67$; "PresentHedonistic", $\mathrm{N}=18, \alpha=.77$ and "Future", $\mathrm{N}=12, \alpha=.75)$ and appear to be satisfactory.

Table 2 gives intercorrelations among principal measures. We can observe significant associations between age and PHTP $(\mathrm{r}=-.20)$ and PFTP $(\mathrm{r}=-.16)$. Several ZTPI subscales correlate strongly, in accordance with previous research (Zimbardo \& Boyd, 1999; Apostolidis \& Fieulaine, 2004). In addition, a significant relationship appears between Future TP and consumption frequency. 


\section{Cannabis Risk Perceptions}

The statistical package STATISTICA was used to carry out a principal components analysis (with varimax rotation) based on the responses to the 22 items concerning the perception of risks linked to cannabis use. Two factors emerged (Scree test, Cattel, 1966) which accounted for 31.5 percent of the total variance. The first factor (eigenvalue $=5.14$; explained variance $=$ $22.3 \%$ ) corresponded to items that clearly indicated a denial of risks induced by cannabis consumption and a positive attitude towards its effects, namely, « Cannabis consumption does not involve any health risks $\gg$. The second factor (eigenvalue $=2.10$; explained variance $=$ 9.2\%) corresponded to items that reflected an attitude which emphasised the risks of cannabis use - this, in fact corresponds to the assimilation of cannabis with "hard drugs". Among these risks, some are well established; others, such as the " escalating theory », are still being debated by the experts, while others are simply proven as non-existent; for example, « to consume cannabis can lead to an overdose ». From these two factors, one can consider the two principal neutralisation strategies described by Peretti-Wattel (2003). On one hand, a "risk denial" dimension and on the other hand, a dimension which reflects the more or less important distinction made between cannabis and "hard" drugs (a stronger agreement with dimension 2 corresponds to an assimilation of cannabis to "hard" drugs). We created two indicators from the mean scores of the items belonging to the same factor after inverting the scores for negative loadings. Thus, we positioned the two indices representing the cannabis risk perceptions, and therefore the cognitive strategies to which they corresponded. The first one was called « risk denial» $(\mathrm{n}=15 ; \alpha=.79 ; \mathrm{m}=2.30 ; \mathrm{SD}=.54)$ and the second " risk assimilation ॥ $(\mathrm{n}=7 ; \alpha=.72 ; \mathrm{m}=2.37 ; \mathrm{SD}=.69)$. No differences between sexes appeared on these indicators.

Table 3 about here

\section{Time perspective and Substance Use}


For each substance consumed, the five ZTPI sub-scale scores were entered as predictors into a logistic regression equation. Odds ratios and $95 \%$ confidence intervals for each predictor are shown in table 4. Some TP scales appeared to be predictive of substance use. Higher scores on FTP decreased the odds of using tobacco and alcohol, while higher scores on Present-Hedonistic TP increased the odds of alcohol consumption. As for cannabis use, the same effects were observed: higher scores on FTP decreased the odds of consuming cannabis while higher scores on PHTP increased them.

Table 4 about here

A simultaneous multiple regression was carried out using the five TP scores as predictors, and the consumption frequency (coded as 1: abstinent to 6 : intensive) and quantity (number of joints smoked) as dependant variables. FTP appeared as a significant predictor in both cases. Thus, a higher level of FTP is related to less frequent $(\beta=-.18 ; p=.01)$ and less important $(\beta=-.19 ; p=.02)$ self-reported cannabis use.

\section{Time Perspective and Risk Perception}

Multiple regressions were also performed in order to predict risk perception from the scores on TP dimensions. Results indicate that some TP dimensions are significant predictors of cannabis risk perception (see table 5). Thus, the more the subjects are oriented towards FTP, the less they emphasise a "risk denial" dimension and the more they emphasise a "risk assimilation" dimension, which is the opposite for PHTP. Finally, higher scores on PastNegative TP are associated with a lower emphasis on "risk denial", and higher scores on Present-Fatalistic TP with a higher emphasis on "risk assimilation".

Table 5 about here

\section{Substance Use and Risk Perception}


In order to examine differences in risk perception between cannabis users and nonusers, an ANOVA was carried out on the data. The analysis revealed significant differences between groups. Users are more likely to emphasise the "risk denial" dimension" $(\mathrm{m}=2.37)$ than non-users $\left(\mathrm{m}=1.88 ; \mathrm{F}(1,198)=35.87 ; \mathrm{p}=.000 ; \eta^{2}=.15\right)$, and non-users are more likely to emphasise the "risk assimilation" dimension $(\mathrm{m}=2.87)$ than users $(\mathrm{m}=2.19 ; \mathrm{F}(1,198)=44.29$; $\left.\mathrm{p}=.000 ; \eta^{2}=.18\right)$.

Regression analyses were performed using consumption frequency and quantity as predictors and risk perceptions as dependant variables. Consumption frequency appeared as a significant predictor of the risk perception. Thus, a higher consumption frequency is associated with a greater emphasis on "risk denial" $\left(\beta=.47 ; \mathrm{R}^{2}=.22, \mathrm{p}=.000\right)$ and a lesser one on "risk assimilation" $\left(\beta=-.52 ; \mathrm{R}^{2}=.27 ; \mathrm{p}=.000\right)$. Consumed quantity was also a significant predictor of the "risk assimilation" dimension $\left(\beta=-.19, \mathrm{R}^{2}=.03 ; \mathrm{p}=.01\right)$.

\section{First Conclusions and Discussion}

In accordance with previous studies, these findings replicate, in the French context, the numerous results established in the literature, showing the predictive value of TP in reported substance use, in particular present and future dimensions; (cf. Keough, Zimbardo \& Boyd, art. cit.). Substance use, as well as cannabis consumption frequency are positively linked to a PH-centred TP and negatively to a Future oriented one. In addition, these results have enabled us to establish that TP is related not only to cannabis consumption behaviours, but also to the risk perceptions related to this consumption. Thus, the denial of risks is negatively linked to the Future TP dimension and positively to the present TP, although inverse relationships were observed concerning the assimilation of cannabis to "hard" drugs. Hence, the link between consumption levels and risk perceptions does appear to be of great importance. In accordance with previous studies, increments in consumption level induce an increase in risk denial and a greater separation of cannabis from harmful drugs (PerettiWattel, 2003). These results can be related to substance redefinition processes and to neutralisation strategies that occur with passing consumption involvement, and they also suggest that the risk perceptions of cannabis use and the related neutralisation strategies are determined simultaneously by TP and the involvement level in consumption. It then remains to determine the role played by the TP variable in the link between levels of use and risk perceptions. 


\section{Examining the TP Variable Status}

In order to explore the role played by TP in the link between cannabis consumption and risk perceptions, we performed a series of analyses aimed at determining the effect of the TP variable in the progression of risk perceptions in relation to the level of consumption. To do so, we tested two types of models, one representing the TP as a mediating variable in the link between consumption levels and risk perceptions and the second representing the TP as a moderating variable in this link.

\section{$\underline{\text { Data Analysis }}$}

We used multiple regression models (Baron \& Kenny, 1986; Judd \& Kenny, 1981) to establish the TP variable status in the link between cannabis consumption levels (the predictor) and risk perceptions (the outcome). The mediational models, tested on each TP dimension and each risk perception indicator, that is to say the 10 models, led us to reject the assumption that the TP variable had a mediating effect in this link. Indeed, the analysis of the standardised regression coefficients did not reveal a significant reduction in the strength of the relationship between the predictor and the outcome variable when TP was added to the model. According to Baron and Kenny (Art. cit.) the hypothesis of such a mediation effect must therefore be rejected.

We then tested the hypothesis of a moderating effect of TP in the link between consumption levels and risk perceptions. The assumption here was that the neutralisation strategies were established in a different way and depended on which TP the individuals identified with. To test this hypothesis, we used multiple regression models (cf. Frazier, Tix \& Baron, 2004), after having centred TP and consumption level (coded as 1: abstinent, 6: intensive) variables. This reconstruction reduced the number of problems associated with multicollinearity (Aiken \& West, 1991). We then created terms of interaction by multiplying together the centred predictor (consumption level) and the mediator (TP). This model was tested on each dimension of the ZTPI and each indicator of risk perception (10 models).

The TP moderating effect was studied using hierarchical regression analysis (Holmbeck, 1997; Cohen \& Cohen, 1983) in order to determine the increase in the explained variance brought into the regression equation by the introduction of interaction term (TP*consumption level, Step 2) compared to the equation containing only the main effects (Step 1). The moderating effect was established only if the interaction terms revealed 
significant regression coefficients and if the increase in variance explained by the model $\left(\Delta \mathrm{R}^{2}\right)$ between step 1 and 2 was significant ${ }^{2}$. The interpretation of this effect was carried out graphically by drawing a diagram, which summarized the form of the moderator effect. This was achieved via simple slope analysis, that is to say, by examining regression lines representing relationships between the predictor (consumption level) and the outcome variable (risk perceptions) for representative groups created by dichotomising the mediator variable (TP: +1 and -1 standard deviation above and below the mean; Cohen, Cohen, West \& Aiken, 2003).

$\underline{\text { Results }}$

The results of the analyses are shown in table 6 . The moderating effect of the TP variable did not appear significant in all cases. Only the Future TP dimension acted as a moderator in the link between consumption level and the denial of risks. This result indicated that the positive relationship observed between the consumption level and the risk denial was stronger when the subjects were more future oriented $(B=.20$ versus $B=.06$ for low scores on FTP, cf. figure 1). Thus, the FTP seemed to support the risk denial related to a high consumption.

Table 6 about here

Concerning the risk assimilation indicator, findings showed that all TP dimensions (except for Past-positive) acted as moderators. Thus, the negative relationship between the consumption level and the risk assimilation was weaker when subjects were present-oriented (hedonistic: $B=-.15$ versus $B=-.28$ for low scores on PHTP and fatalistic: $B=-.11$ versus $B=-.29$ for low scores on PFTP, cf. figures 2 and 3). The same effect appeared for Past-negative $(B=-.05$ versus $B=-.26$ for low scores on PNTP, cf. figure 4). However, when we considered the FTP, we observed the opposite effect. Thus, the negative relationship between consumption level and an "assimilation" indicator was stronger when individuals were more future oriented $(\mathrm{B}=-$ .33 versus $\mathrm{B}=-.04$ for low scores on $\mathrm{FTP}$, cf. figure 5).

\footnotetext{
${ }^{2}$ Test of significance of the $R^{2}$ increment $\left(\Delta R^{2}\right)$ is provided by the $F$ test : $F=\left[\left(R_{2}{ }^{2}-R_{1}{ }^{2}\right) /\left(k_{2}-k_{1}\right)\right] /\left[\left(1-R_{2}{ }^{2}\right) /\left(n-k_{2}-1\right)\right]$; where DL are $\left(k_{2}-k_{1}\right)$ and $\left(n-k_{2}-1\right), n=$ total sample size; $k_{2}=$ number of predictors at step $2, k_{1}=$ number of predictors at step $1 ; R_{1}{ }^{2}$ and $R_{2}{ }^{2}=$ explained variance for the first and the second model (Cohen \& Cohen, 1983).
} 


\section{Conclusions : The Moderating Effect of TP}

These results give support to the hypothesis of an intervening TP variable in redefining risk strategies linked to the level of cannabis consumption. The fact that TP intervenes specifically in the case of assimilation to "hard" drugs, shows that these two cognitive neutralisation strategies are partially distinct and are based on specific reasoning. The "separation" therefore established between cannabis and "hard" drugs, thus appears to be marked by a temporal component. More precisely, it is linked to the temporality to which the individuals identify with.

This moderating effect acts in different ways according to certain temporal frames. The future dimension intervenes simultaneously in the risk denial and the assimilation of cannabis to a "hard" drug. Focusing on the Future leads to a larger denial of risks and a stronger disaccord with the assimilation of cannabis to hard drugs when consumption increases. Conversely, emphasis of the Present (fatalistic or hedonistic) is accompanied by a greater assimilation. In addition, focusing on the Past-negative dimension has a similar effect as that of focusing on the Present. This moderating effect shows that TP intervenes in substance redefinition and in the neutralisation of labelling strategies; not in the nature of these processes, but rather in the level in which they are mobilised.

\section{GENERAL DISCUSSION}

Several findings from this study highlight the complexity of cannabis use and abuse when considering social behaviours and the importance of the TP variable for analysing this complexity.

Firstly, this study provides further support to the results already established in the literature concerning the predictive value of TP (Keough, Zimbardo \& Boyd, 1999) and the mobilisation of neutralisation strategies concerning consumption (Peretti-Wattel, 2003). In accordance with previous studies, substance use and cannabis consumption are positively linked to a present-centred TP, and negatively to a future-oriented one. As the level of consumption increases we observe a greater denial of risks and a stronger disaccord with the assimilation cannabis to "hard" drugs. Additionally, findings showed a link between TP and 
cannabis risk perceptions that had not previously been considered. Thus, denial of risk is positively linked to a present-centred TP, and negatively to a future oriented one, which is the contrary to the assimilation of cannabis to "hard" drugs.

As consumption increases, substance definition becomes more complex. When simultaneously taking into account cannabis use behaviours, the related risk perceptions and the TP variable, we can observe that TP effects that appear are more complex than was previously established. Thus, for example, if FTP constitutes, and is generally considered as, a brake in the initiation of consumption, it may in fact facilitate a more regular consumption by supporting cognitive adjustments represented by neutralisation strategies. More precisely, the way in which FTP acts as a moderator on the relationship between consumption behaviours and risk perceptions related to cannabis shows that, far from establishing a consumption barrier, FTP can in fact support adhesion to a vision of the substance, that is to say, more denial and less assimilation to "hard" drugs, resulting in acceptability of consumption. It is possible to note here that when installation in consumption behaviour involves an anticipatory dimension, the FTP effect on the mobilisation of neutralisation strategies can reflect a specific construction of an adapted relationship with the substance.

These results demonstrate the temporally marked character of engagement in substance use behaviours and beyond the level of these behaviours, their cognitive anchoring in a present or future oriented TP. They also demonstrate the necessity of further research so as to understand exactly how neutralisation strategies - denial and assimilation - are affected by FTP as regards repeated use and to provide more empirical information about the relevant psychosocial dynamics.

In addition, these results highlight the stakes that contemporary cannabis use raises. If the relationship with the substance and the related socio-cognitive dimensions for analysing cannabis use is taken in to account, it suggests that cannabis users can no longer be labelled as "drug-takers". It is also relevant to think about the significance of a planning attitude, as is measured by FTP, when substance consumption plays an important part in individuals' lives. In order to understand how cannabis use fits into users' everyday lives more precisely and effectively, it is necessary to study the "normalisation" context concerning use among young adults. As cannabis use becomes a more prevalent mass behaviour, it is no longer possible to analyse the nuances and the complexities of how it fits only into abnormal or deviant-derived explanations (Hammersley \& al., 2001). The fundamental contradictory character of cannabis and the social debates that it provokes highlight the necessity of understanding how users deal with this contradiction with regard to their level of use. Findings show that this level cannot 
be considered as linearly linked to substance perceptions when related socio-cognitive variables are taken into account.

However, several limitations of the findings of this study should be noted. Firstly, our sample constituted of young university students, and clearly, results from such a group might not generalise all other groups. Secondly, limitations inherent in the scale used for measuring TP must be extended to the findings. Thus, ZTPI cannot thoroughly describe the temporality of individuals or groups. This element emphasises the fact that temporality is a more complex object than TP measured by ZTPI, especially the FTP structure which is related to a planning and achievement dimension. Thirdly, the measures employed for substance use were all selfreported. It would be useful in future studies to consider obtaining behaviour reports from peers or from more standardised behaviour questionnaires. Additionally, it should be noted that data are cross-sectional and cannot be, without any question, considered as representing any development in consumption behaviours. Passing from repeated consumption to a regular one involves more complex processes than inter-individual comparisons. However, as PerettiWattel noted (2003), these comparisons between consumption levels are a useful way of exploring the psychosocial dynamics of consumption behaviours, and allow relevant observations for future longitudinal studies. Finally, the specific character of cannabis perception studied here limits findings. Indeed, perception of a consumed substance cannot be limited to risk perception and we can observe this lack of thoroughness in the results of factorial analysis (explained variance). This aspect is just one amongst many others, and the relationship with cannabis cannot only be described in this way. Future research should take this complexity into consideration, even if the cognitive adjustment in risk perception is a central aspect of the relationship to the substance with regard to its development.

Despite these limitations, this study has established interesting points for analysing the determinants and correlates of substance use, and offers a useful approach in the study of consumption development, quitting or relapse. In particular, the role played here by TP appears to pose a stake within the framework of developing prevention programmes, in that the emphasis on temporality in which individuals find themselves, is given different significance for similar behaviours. This last element highlights the need for future research aimed at understanding, in more detail, firstly the relationship between the maintenance of consumption behaviours and the perceptions of the consumed substance, and secondly, the psychosocial dynamics implied in the evolution of consumption. Such a perspective necessitates taking into account socio-cognitive dimensions that intervene in the development and the dynamics of the significations attached to the behaviours, and which highlights the 
interest of a non-pathological approach to substance use behaviours. This suggests that for Health Psychology, future research focusing on these different dimensions may allow for more precise analyses of these complex social behaviours related to contemporary cannabis use in Europeans countries.

\section{ACKNOWLEDGEMENTS}

We would like to thank Michel Morin and Patrick Scharnitzky for their suggestions regarding earlier version of this paper. 


\section{References}

Aiken, L.S. \& West, S.G. (1991) Multiple regression: Testing and interpreting interactions. Newbury Park: Sage.

Alvos, L., Gregson, R.A. \& Ross, M.W. (1993) Future Time Perspective in current and previous injecting drug users. Drug and Alcohol Dependence, 31, 193-197.

Apostolidis, T. \& Fieulaine, N. (2004) Validation française de l'échelle de temporalité The Zimbardo Time Perspective Inventory. European Review of Applied Psychology, 54, 207-217.

Baron, R.M. \& Kenny, D.A. (1986) The moderator-mediator variable distinction in social psychological research: Conceptual, strategic, and statistical considerations. Journal of Personality and Social Psychology, 51, 1173-1182.

Beck, F., Legleye, S. \& Perretti-Wattel, P. (2002) Santé, mode de vie et usages de drogues à 18 ans. Paris: OFDT.

Beck, F. \& Legleye, S. (2003a) Evolutions récentes des usages de drogues à 17 ans : ESCAPAD 2000-2002. Tendance, 29. Paris : OFDT.

Beck, F. \& Legleye, S. (2003b) Les adultes et les drogues en France: Niveaux d'usage et évolutions récentes. Tendance, 30. Paris: OFDT.

Boney-McCoy, S.B., Gibbons, F.X., Reis, T.J., Gerrard, M., Luus, C.A. \& VonWald Suka, A. (1992) Perceptions of smoking risk as a function of smoking status. Journal of Behavioral Medicine, 15, 469-488.

Cattell, R.B. (1966) The scree test for the number of factors. Multivariate behavioural research, 1, 246-276.

Choquet, M., Beck, F., Hassler, C., Spilka, S., Morin, D. \& Legleye, S. (2004) Les substances psychoactives chez les collégiens et lycéens: Consommations 2003 et évolutions depuis 10 ans. Tendances, 35. Paris: OFDT.

Cohen, J. \& Cohen, P. (1983) Applied multiple regression/correlation analysis for the behavioural sciences. Hillsdale : Erlbaum.

Cohen, J., Cohen, P., West, S.G. \& Aiken, L.S. (2003) Applied multiple regression/correlation analysis for the behavioural sciences ( ${ }^{\text {rd }}$ ed.). Mahwah, $\mathrm{NJ}$ : Erlbaum.

Dany, L. \& Apostolidis, T. (2002) A study on the social representations of drugs and cannabis: The issues and what is a stake for prevention. Santé Publique, 14, 335-344.

Frazier, P.A., Tix, A.P. \& Baron, K.E. (2004) Testing moderator and mediator effects in counseling psychology research. Journal of Counseling Psychology, 51, 115-134.

Gerrard, M., Gibbons, F.X., Benthin, A.C. \& Hessling, R.M. (1996) A longitudinal study of the reciprocal nature of risk behaviors and cognitions in adolescents: What you do shapes what you think and vice versa. Health Psychology, 15, 344-354.

Gibbons, F.X., Tami, J.E. \& Alida, C.B. (1997) Cognitive reactions to smoking relapse: The reciprocal relation between dissonance and self-esteem. Journal of Personality and Social Psychology, 72, 184-195.

Hall, P.A. \& Fong, G.T. (2003) The effects of a brief Time Perspective intervention for increasing physical activity among young adults. Psychology \& Health, 18, 685-706.

Hammersley, R.; Jenkins, R. \& Reid, M. (2001) Cannabis use and social identity. Addiction Research \& Theory, 9, $133-150$.

Holmbeck, G.N. (1997) Toward terminological, conceptual, and statistical clarity in the study of mediators and moderators: Examples from the child-clinical and psychology literatures. Journal of Counseling and Clinical Psychology, 65, 399-410.

Hulbert, R.J. \& Lens, W. (1988) Time Perspective, Time Attitude, and Time Orientation in alcoholism: A review. International Journal of Addictions, 23, 279-298.

Joffe, H. (2003) Risk: From perception to social representation. British Journal of Social Psychology, 42, 55-73.

Judd, C.M. \& Kenny, D.A. (1981) Process Analysis: Estimating mediation in treatment evaluations. Evaluation Review, 5, 602-619.

Keough, K.A., Zimbardo, P.G. \& Boyd, J.N. (1999) Who's smoking, drinking and using drugs? Time perspective as a predictor of substance use. Journal of Basic and Applied Social Psychology, 21, 149-164.

King, M.R. \& Manaster, G.J. (1975) Time perspective correlates of collegiate cannabis use. Journal of Consulting and Clinical Psychology, 43, 99.

Levy, B. \& Earleywine, M. (2004) Discriminating reinforcement expectancies for studying from future time perspective in the prediction of drinking problems. Addictive Behaviors, 29, 181-190.

Lewin, K. (1942) Time Perspective and Morale. In G. Watson (Ed.), Civilian Morale. Boston : Houghton Mifflin, 48-70.

Lipscomb, J. (1989) Time preference for health in cost-effectiveness analysis. Medical Care, 27, $233-253$.

McCusker, C.G., Roberts, G., Douthwaite, J. \& Williams, E. (1995) Teenagers and illicit drug use: Expanding the "users vs. non-users" dichotomy. Journal of Community \& Applied Psychology, 5, 221-241.

McMillan, B., Sherlock, K. \& Conner, M. (2003) Expanding the Traditional User versus Non-User Dichotomy amongst Ecstasy Users. Journal of Community \& Applied Psychology, 13, 15-28.

Pearson, G. (2001) Normal Drug Use: Ethnographic fieldwork among an adult network of recreational drug users in inner London. Substance Use and Misuse, 36, 167-200. 
Peretti-Wattel, P. (2003) Neutralization theory and the denial of risk: Some evidence from cannabis use among French adolescents. British Journal of Sociology, 54, 21-42.

Peretti-Wattel, P. (2000) Sociologie du risque. Paris: Armand Colin.

Petry, N.M. \& Bickel, W.K. (1998) Polydrug abuse in heroin addicts: A behavioral economic analysis. Addiction, 93, 321-335.

Resnicow, K., Smith, M., Harrison, L. \& Drucker, E. (1999) Correlates of occasional cigarettes and cannabis use: Are teens harms reducing? Addictive Behaviors, 24, 251-266.

Rosenbloom, T. (2003) Risk evaluation and risky behavior of high and low sensation seekers. Social Behavior and Personality, 31, 375-386.

Strickland, L.H., Lewicki, R.J. \& Katz, A.M. (1966) Temporal Orientation and perceived control as determinants of risk-taking. Journal of Experimental Social Psychology, 2, 143-151.

Wilde, G.J.S. (1982) The theory of Risk Homeostasis: Implications for safety and health. Risk Analysis, 2, 209225.

Wills, T.A., Sandy, J.M. \& Yaeger, A.M. (2001) Time perspective and early-onset substance use: A model based on stress-coping theory. Psychology and Addictive Behavior, 15, 118-125.

Zimbardo, P.G. \& Boyd, J.N. (1999) Putting time in perspective: A valid, reliable individual-differences metric. Journal of Personality and Social Psychology, 77, 1271-1288. 
TABLE 1.

Demographic data, drug use characteristics and TP scores.

\begin{tabular}{|c|c|c|}
\hline Variable & Men & Women \\
\hline$\overline{\mathrm{N}}$ & 100 & 98 \\
\hline Mean Age (SD) & $22.3(2.02)$ & $21.3(1.77)$ \\
\hline \multicolumn{3}{|c|}{ Self-reported consumption ( $\%$ ever consumed) } \\
\hline Cannabis & 76 & 71.4 \\
\hline Tobacco & 92 & 88.7 \\
\hline Alcohol & 70 & 76.5 \\
\hline Ecstasy & 17 & 14.3 \\
\hline LSD & 14 & 7.1 \\
\hline Cocaine & 18 & 10.2 \\
\hline Heroin & 6 & 2 \\
\hline \multicolumn{3}{|c|}{ Cannabis consumption level (\% in consumers) } \\
\hline Experimental & 15.6 & 25.7 \\
\hline Occasional & 23.3 & 28.6 \\
\hline Repeated & 14.4 & 17 \\
\hline Regular & 20.7 & 14.4 \\
\hline Intensive & 26 & 14.3 \\
\hline \multicolumn{3}{|c|}{ Time perspective (m, SD) } \\
\hline Past-positive & $3.41(.60)$ & $3.50(.60)$ \\
\hline Past-negative & $3.00(.70)$ & $2.92(.73)$ \\
\hline Present-fatalistic & $2.53(.60)$ & $2.60(.71)$ \\
\hline Present-hedonistic & $3.45(.51)$ & $3.45(.49)$ \\
\hline Future & $3.14(.54)$ & $3.22(.65)$ \\
\hline
\end{tabular}


TABLE 2.

Mean scores, standard deviations and intercorrelations $(N=198)$.

\begin{tabular}{|c|c|c|c|c|c|c|c|c|c|}
\hline Measure & $\mathrm{M}$ & SD & 1 & 2 & 3 & 4 & 5 & 6 & 7 \\
\hline 1. Age & 21.8 & 1.96 & -- & & & & & & \\
\hline 2. Past-Positive & 3.45 & .60 & .08 & -- & & & & & \\
\hline 3. Past-Negative & 3.07 & .61 & -.05 & $-.23 * *$ & -- & & & & \\
\hline 4. Present-Fatalistic & 2.41 & .66 & $-.16^{*}$ & $-.18 * *$ & $.34 * * *$ & -- & & & \\
\hline 5. Present-hedonistic & 3.32 & .47 & $-.20 * *$ & -.06 & .12 & $.36^{* * *}$ & -- & & \\
\hline 6. Future & 3.18 & .60 & .12 & $.15^{*}$ & -.08 & $-.31 * * *$ & $-.33 * * *$ & -- & \\
\hline 7. Consumption level ${ }^{\mathrm{a}}$ & 3.16 & 1.78 & -.11 & .03 & -.10 & .01 & .13 & $-.19 * *$ & -- \\
\hline
\end{tabular}


TABLE 3.

Opinions about risks involved using cannabis.

Principal component analysis: Varimax-rotated matrix

Note: We presented only loadings $\geq 30$.

Risk

Risk

Denial Assimilation

Items

1. Cannabis does not disturb the mental equilibrium of the consumer.

.632

$(\alpha=.72)$

$\mathrm{M} \quad \mathrm{SD}$

2. Cannabis consumption does not interfere with school or professional

.603

$2.32 \quad 1.00$

activities.

3. Cannabis consumption does not involve health risks

.594

$2.10 \quad 1.120$

4. People who buy cannabis have nothing to fear from the dealers

.566

$2.39 \quad 1.03$

5. Cannabis is a drug.

$-.516$

$4.16 \quad 1.02$

6. It is not dangerous to drive after having consumed cannabis

.506

$1.87 \quad 1.15$

7. Cannabis consumption does not affect the neurons

.488

8. Smoking cannabis is not bad for the memory

.480

2.04

0.93

9. After consuming cannabis, one is motivated to work

.477

$1.92 \quad 1.08$

10. Simultaneous consumption of alcohol and cannabis multiplies the risks

of losing self-control

11. Smoking cannabis facilitates the discussion between the smokers and non smokers

12. Cannabis consumption makes one lose self-control

13. Cannabis amplifies emotions in a positive way

14. Cannabis does not lead to psychological dependence

15. Cannabis consumption leads to problems of a sexual nature

16. Consuming cannabis destroys friendly relationships

17. Consuming cannabis can lead to an overdose

18. Cannabis consumption leads to the consumption of other drugs

19. Cannabis leads to physical dependence

20. Smoking cannabis causes eczema

21. Cannabis is more dangerous than alcohol for the health 
TABLE 4.

Summary of logistic regression analyses predicting Tobacco, Alcohol and Cannabis Use.

\begin{tabular}{|c|c|c|c|}
\hline & Tobacco Use & Alcohol Use & Cannabis Use \\
\hline & OR $(95 \%$ CI $)$ & OR $(95 \% C I)$ & OR $(95 \% C I)$ \\
\hline Past-Negative & $1.26(0.75-2.12)$ & $0.41(0.16-1.00)^{*}$ & $0.80(0.48-1.34)$ \\
\hline Past-Positive & $1.33(0.74-2.42)$ & $0.54(0.19-1.52)$ & $1.53(0.87-2.79)$ \\
\hline Present-Hedonistic & $1.40(0.66-2.96)$ & $8.14(2.33-28.40)^{* * *}$ & $2.26(1.06-4.84)^{*}$ \\
\hline Present-Fatalistic & $0.96(0.52-1.77)$ & $0.62(0.23-1.69)$ & $0.87(0.48-1.58)$ \\
\hline Future & $0.32(0.17-0.62)^{* * *}$ & $0.29(0.10-0.80)^{* *}$ & $0.50(0.27-0.91)^{*}$ \\
\hline \multicolumn{4}{|l|}{ Model } \\
\hline $\mathrm{Chi}^{2}(5)$ & $19.74 * * *$ & $27.13 * * *$ & $17.32 * *$ \\
\hline $\mathrm{R}^{2}$ (Nagelkerke) & .14 & .25 & .12 \\
\hline
\end{tabular}


TABLE 5.

Regression estimates ( $\beta$ s) predicting risk perception.

\begin{tabular}{lcc}
\hline \hline & Risk & Risk \\
& Denial & Assimilation \\
\hline \hline Past-Negative & $-.13^{*}$ & .09 \\
Past-Positive & -.08 & -.00 \\
Present-Fatalistic & .01 & $.15^{*}$ \\
Present-Hedonistic & $.18^{* *}$ & $-.19^{* *}$ \\
Future & $-.16^{*}$ & $.28^{* * *}$ \\
$\mathrm{R}^{2}$ & .09 & .14 \\
\hline$* \mathrm{p} \leq 05 ; * * \mathrm{p} \leq 01 ; * * \mathrm{p} \leq 001$ & &
\end{tabular}

${ }^{*} \mathrm{p} \leq .05 ;{ }^{* *} \mathrm{p} \leq .01 ; * * * \mathrm{p} \leq .001$. 
TABLE 6.

Test of moderating effect of TP.

\begin{tabular}{|c|c|c|c|c|c|c|c|c|}
\hline & \multicolumn{4}{|c|}{ Risk Perception : « Denial » } & \multicolumn{4}{|c|}{ Risk Perception : «Assimilation » } \\
\hline & \multicolumn{2}{|c|}{ Step 1} & \multicolumn{2}{|c|}{ Step 2} & \multicolumn{2}{|c|}{ Step 1} & \multicolumn{2}{|c|}{ Step 2} \\
\hline & $\beta$ & $p$ & $\beta$ & $p$ & $\beta$ & $p$ & $\beta$ & $p$ \\
\hline PH TP & .18 & .004 & .17 & .007 & -.15 & .018 & -.14 & .01 \\
\hline Consumption & .43 & .000 & .43 & .000 & -.54 & .000 & -.55 & .000 \\
\hline $\mathrm{PH} *$ Cons. & -- & -- & -.04 & ns & -- & -- & .11 & .05 \\
\hline$R_{1}^{2}, R_{2}^{2}$ & \multicolumn{2}{|c|}{$\mathrm{R}_{1}^{2}=.25$} & \multicolumn{2}{|c|}{$\mathrm{R}_{2}^{2}=.25$} & \multicolumn{2}{|c|}{$\mathrm{R}_{1}^{2}=.34$} & \multicolumn{2}{|c|}{$\mathrm{R}_{2}^{2}=.36$} \\
\hline$\Delta R^{2}, p$ & \multicolumn{4}{|c|}{$\Delta \mathrm{R}^{2}: \mathrm{ns}$} & \multicolumn{4}{|c|}{$\Delta \mathrm{R}^{2}=.02, \mathrm{p}=.01$} \\
\hline F TP & -.14 & .03 & -.11 & .09 & .20 & .001 & .15 & .01 \\
\hline Consumption & .44 & .000 & .45 & .000 & -.48 & .000 & -.48 & .000 \\
\hline $\mathrm{F} *$ Cons. & -- & -- & .11 & .05 & -- & -- & -.20 & .001 \\
\hline$R_{1}^{2}, R_{2}^{2}$ & \multicolumn{2}{|c|}{$\mathrm{R}_{1}^{2}=.24$} & \multicolumn{2}{|c|}{$\mathrm{R}_{2}^{2}=.26$} & \multicolumn{2}{|c|}{$\mathrm{R}_{1}^{2}=.30$} & \multicolumn{2}{|c|}{$\mathrm{R}_{2}^{2}=.35$} \\
\hline$\Delta R^{2}, p$ & \multicolumn{4}{|c|}{$\Delta \mathrm{R}^{2}=.02, \mathrm{p}=.02$} & \multicolumn{4}{|c|}{$\Delta \mathrm{R}^{2}=.05, \mathrm{p}=.000$} \\
\hline PF TP & .06 & ns & .05 & $\mathrm{~ns}$ & .03 & $\mathrm{~ns}$ & .04 & $\mathrm{~ns}$ \\
\hline Consumption & .47 & .000 & .47 & .000 & -.52 & .000 & -.53 & .000 \\
\hline $\mathrm{PF} *$ Cons. & -- & -- & -.09 & $\mathrm{~ns}$ & -- & -- & .17 & .004 \\
\hline$R_{1}^{2}, R_{2}^{2}$ & \multicolumn{2}{|c|}{$\mathrm{R}_{1}^{2}=.23$} & \multicolumn{2}{|c|}{$\mathrm{R}_{2}^{2}=24$} & & & \multicolumn{2}{|c|}{$\mathrm{R}_{2}^{2}=.30$} \\
\hline$\Delta R^{2}, p$ & \multicolumn{4}{|c|}{$\Delta \mathrm{R}^{2}: \mathrm{ns}$} & \multicolumn{4}{|c|}{$\Delta \mathrm{R}^{2}=.03, \mathrm{p}=.001$} \\
\hline PN TP & -.03 & $\mathrm{~ns}$ & -.03 & $\mathrm{~ns}$ & .04 & ns & .05 & ns \\
\hline Consumption & .47 & .000 & .47 & .000 & -.52 & .000 & -.51 & .000 \\
\hline PN * Cons. & -- & -- & -.03 & ns & -- & -- & .12 & .04 \\
\hline$R_{1}^{2}, R_{2}^{2}$ & \multicolumn{2}{|c|}{$\mathrm{R}_{1}^{2}=.22$} & \multicolumn{2}{|c|}{$\mathrm{R}_{2}^{2}=.22$} & & & \multicolumn{2}{|c|}{$\mathrm{R}_{2}^{2}=.29$} \\
\hline$\Delta R^{2}, p$ & \multicolumn{4}{|c|}{$\Delta \mathrm{R}^{2}: \mathrm{ns}$} & \multicolumn{4}{|c|}{$\Delta \mathrm{R}^{2}=.02, \mathrm{p}=.02$} \\
\hline PP TP & -.08 & ns & -.07 & $\mathrm{~ns}$ & .00 & $\mathrm{~ns}$ & -.01 & ns \\
\hline Consumption & .47 & .000 & .48 & .000 & -.52 & .000 & -.52 & .000 \\
\hline PP * Cons. & -- & -- & .06 & $\mathrm{~ns}$ & -- & -- & -.08 & ns \\
\hline$R_{1}^{2}, R_{2}^{2}$ & \multicolumn{2}{|c|}{$\mathrm{R}_{1}^{2}=.23$} & \multicolumn{2}{|c|}{$\mathrm{R}_{2}^{2}=.23$} & & & \multicolumn{2}{|c|}{$\mathrm{R}_{2}^{2}=.27$} \\
\hline$\Delta R^{2}, p$ & & & $2: \mathrm{ns}$ & & & & $: \mathrm{ns}$ & \\
\hline
\end{tabular}

Note. $\mathrm{R}^{2}=$ explanation rate for each step, $\Delta \mathrm{R}^{2}=$ change in explanation rate between step 1 and step 2 . 
FIGURE 1. Moderating Effect of Future Time Perspective between consumption level and risk perception ("Denial")

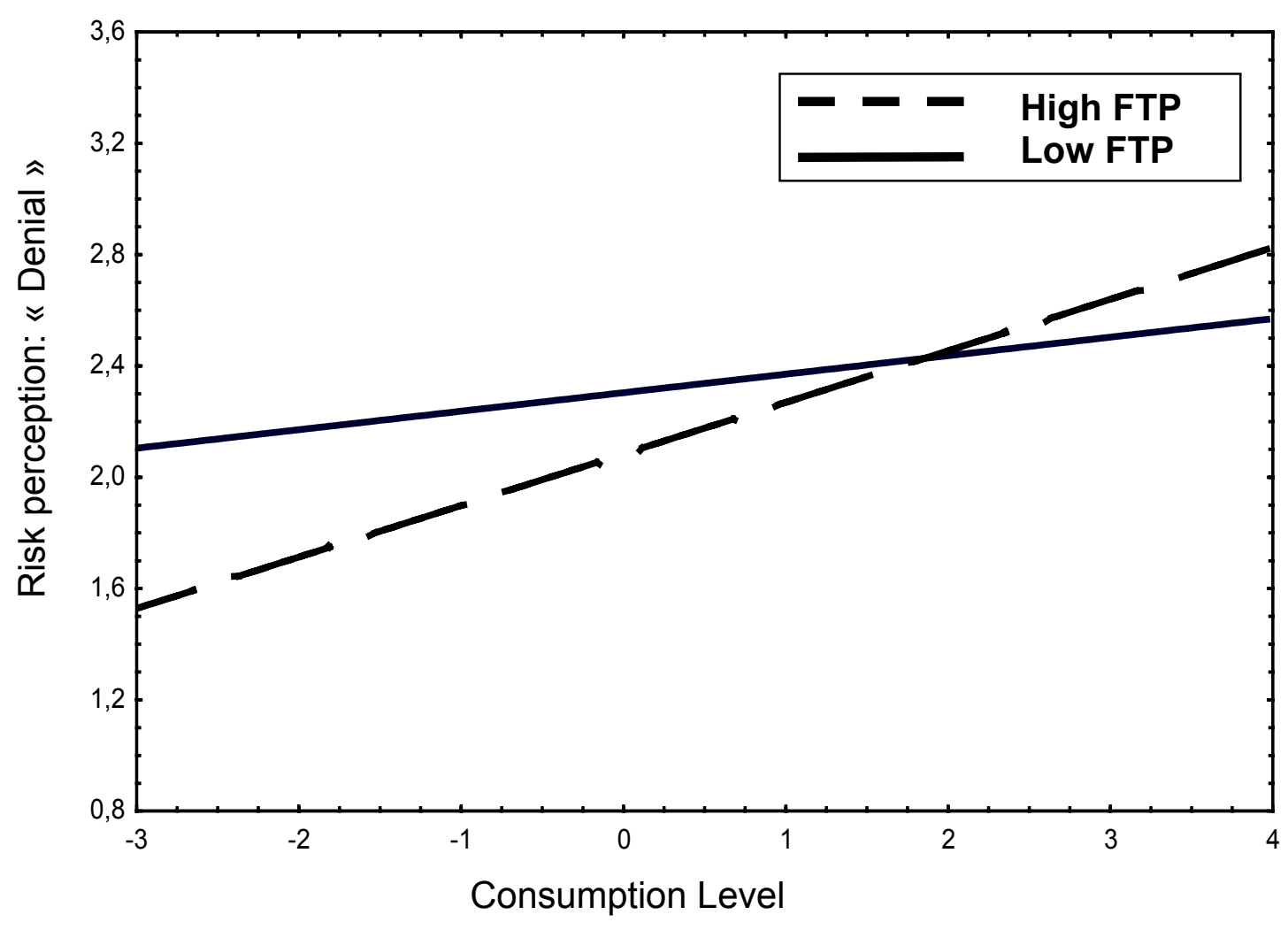


FIGURE 2. Moderating effect of Present-Hedonistic Time Perspective between consumption level and risk perception ("Assimilation")

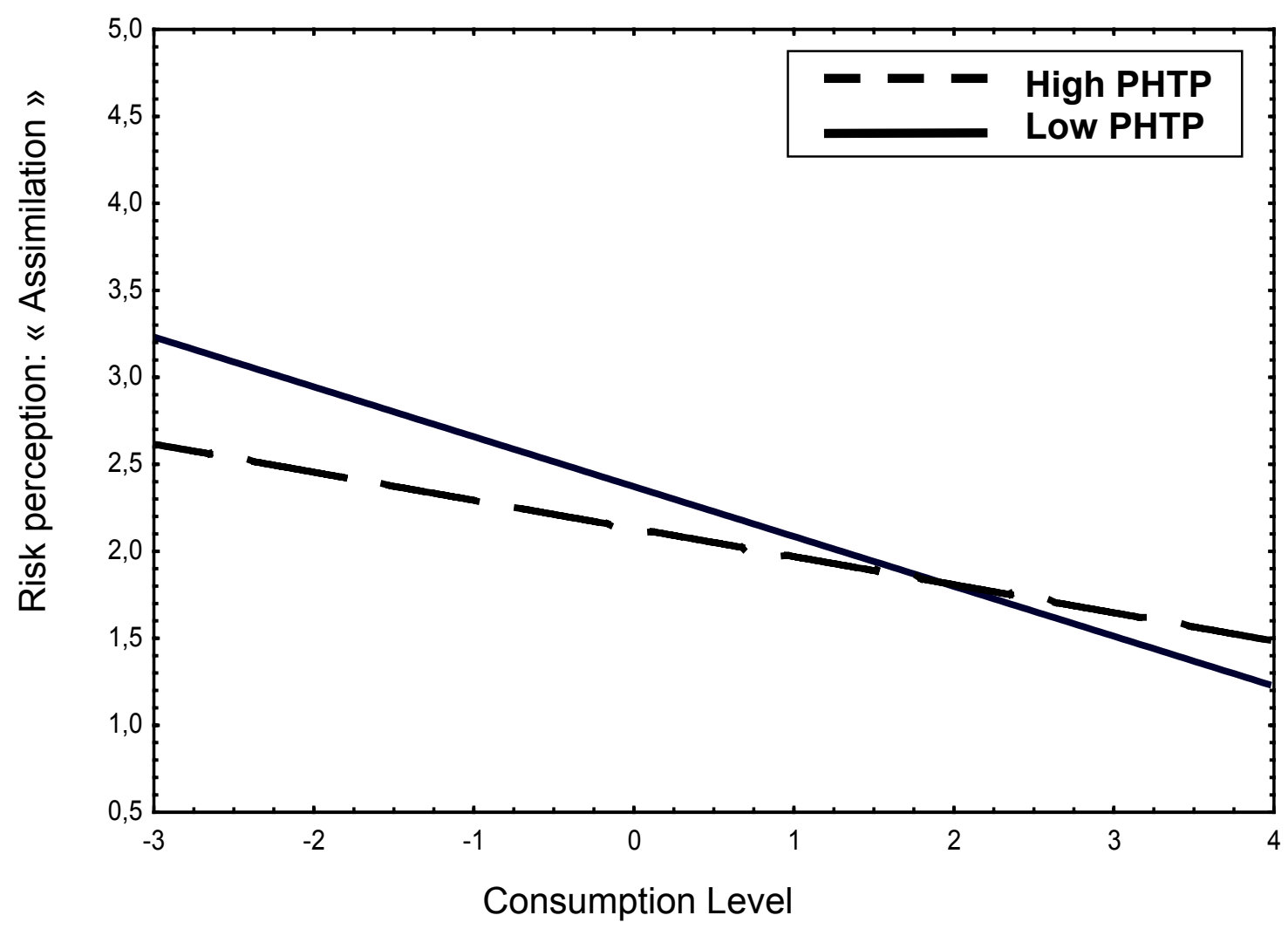


FIGURE 3. Moderating effect of Present-Fatalistic Time Perspective between consumption level and risk perception ("Assimilation")

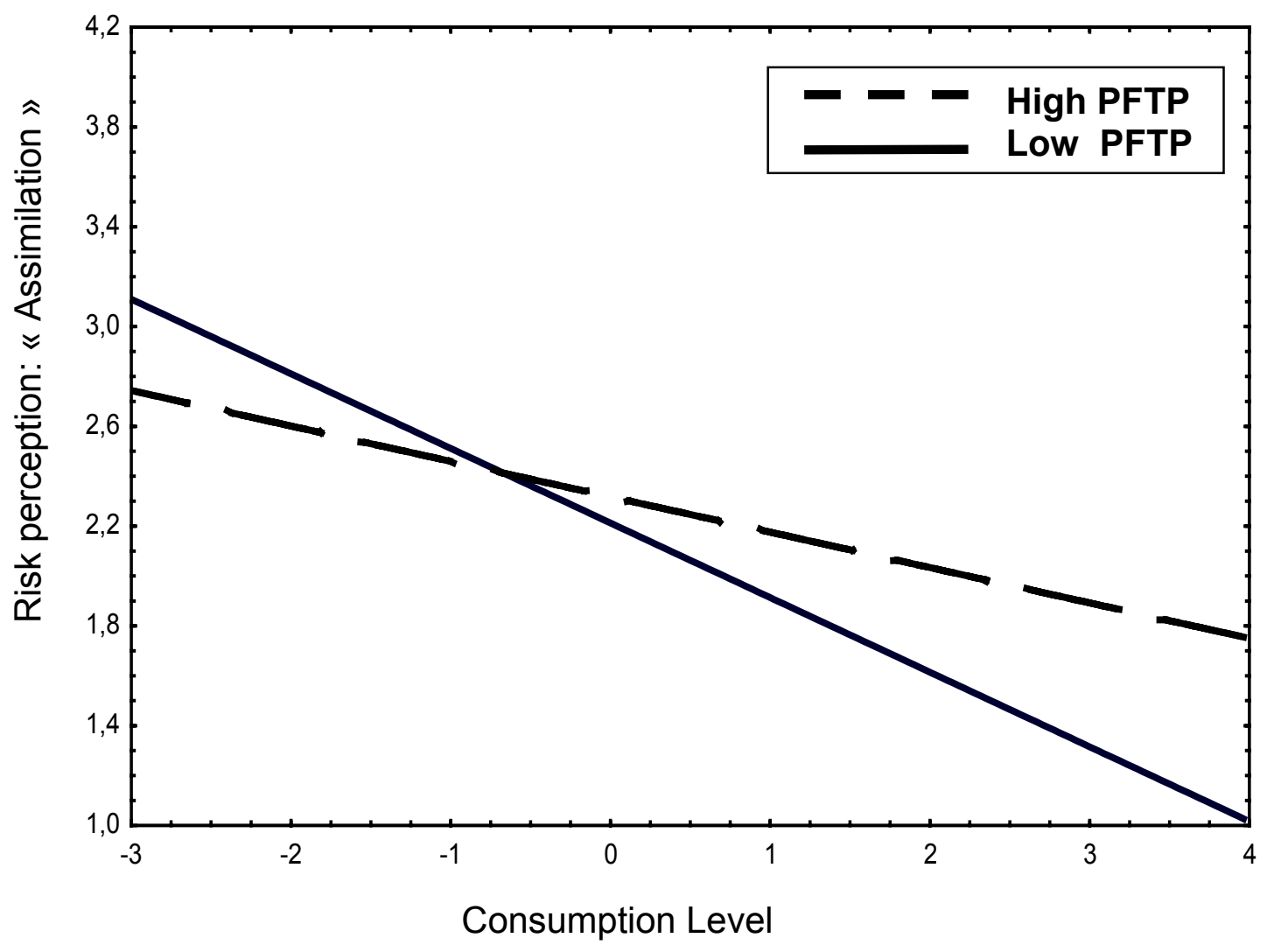


FIGURE 4. Moderating effect of Past-Negative Time Perspective between consumption level and risk perception ("Assimilation")

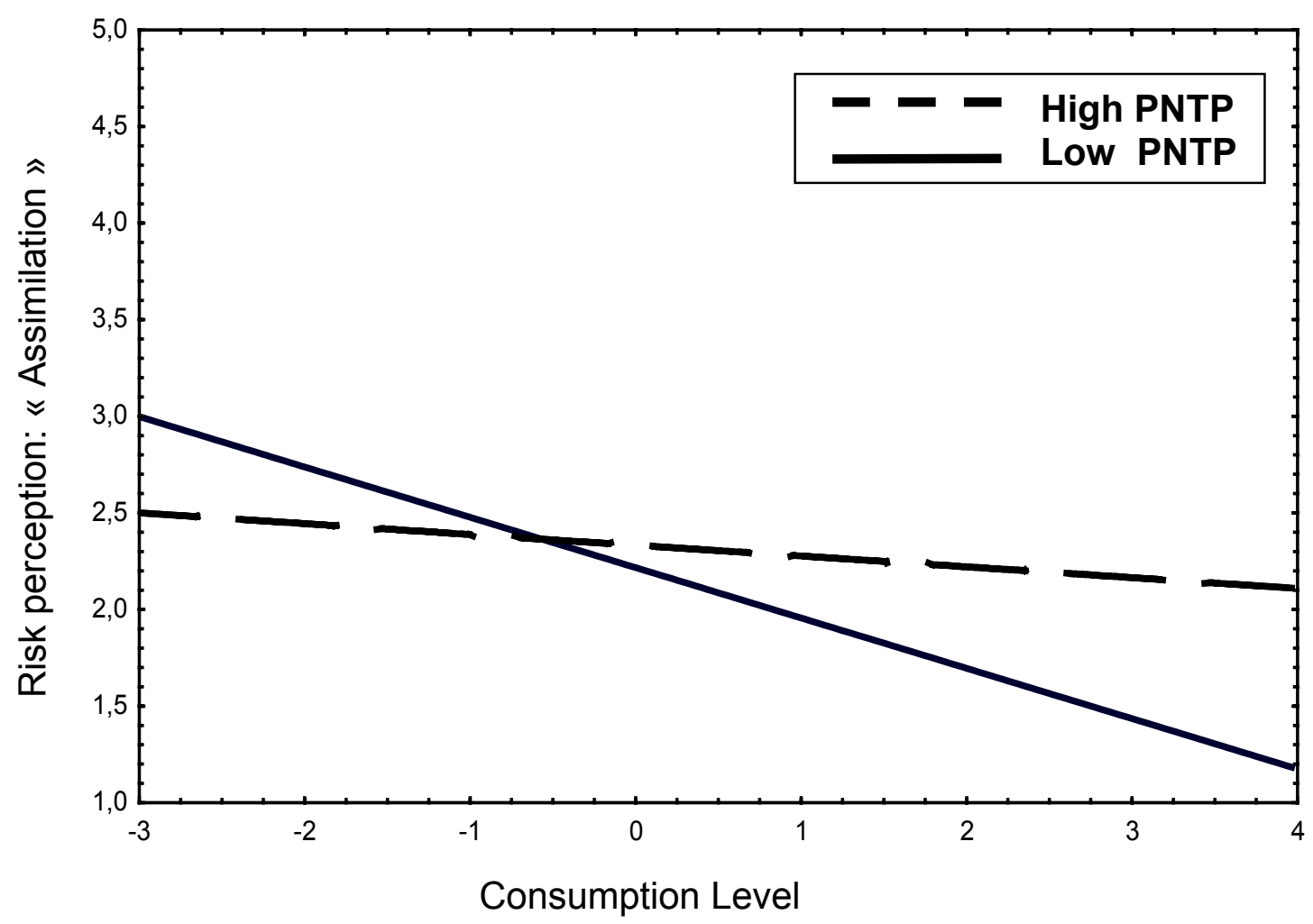


FIGURE 5. Moderating Effect of Future Time Perspective between consumption level and risk perception ("Assimilation")

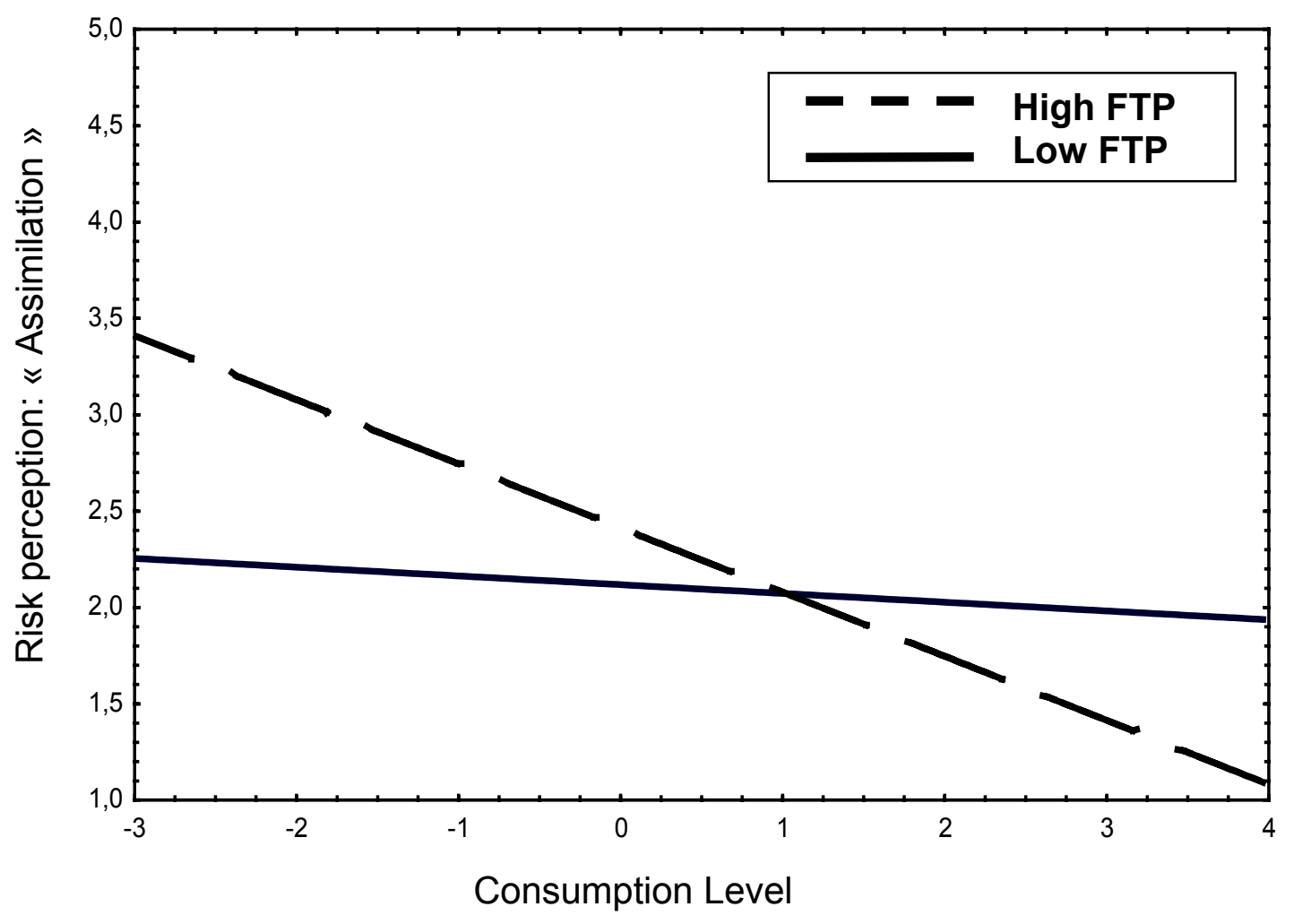

